\title{
Esthesioneuroblastoma - A Rarity
}

\begin{abstract}
Raman Arora - Senior Consultant Medicine and Oncology, Parminder Singh- Senior Resident, Medicine, Department of Endocrinology, P. G. I., Chandigarh, T. N. Shadangi - Head of the Department of Neuro-Surgery, Dayanand Medical College, Ludhiana. Manmohan Singh - Head ENT Department, Mohan Dai Oswal Cancer Treatment \& Reserch Foundation, G. T. Road, Sherpur, Bye-Pass, Ludhiana.
\end{abstract}

\section{Abstract}

A young male presented with visual complaints of one year duration, epistaxis and nasal blockage of 3 months duration. He had bilateral proptosis and bitemporal hemianopia and a mass near the roof of nasal cavity. Skull skiagram showed enlarged sella and computed tomography showed erosion of sella and a central mass. Partial excision of supra and parasellar tumour was done which on histopatho-logical examination revealed Esthesioneuroblastoma. This was followed by radiotherapy and CCNU twice, at 6 weeks interval. He is doing well after 1 year and 9 months of follow up.

M r. R. K., 26 years old, healthy, non smoker, Hindu male presented in August 1990 with complaints of eyeache, gradual decrease in acuity of vision of one year duration; now having nasal field vision from right eye since a month and from left eye 15 days. He had recurrent epistaxis and nasal blockage from three months. There was no history of headache, vomitting, fever, trauma or seizures.

On examination he was conscious, co-operative and fully oriented. ENT examination revealed bilateral turbinate hypertrophy and a greyish mass near the roof of nasal cavity. Examination of the nervous system was normal except visual field charting showing bitemporal hemianopia. Opthalmic examination revealed bilateral proptosis with visual acuity of 6/6 from left and 6/18 from right eye. Hemogram and biochemical parameters were within normal limits as was chest skiagram. X-ray skull showed large sella with temporal bone erosion. Computerised Tomography scan showed suprasellar mass with parasellar extension ( fig I and II). Bone scan and urinary vanillylmandelic Acid (VMA) were normal.

Right fronto-temporal craniotomy and partial excision of suprasellar and parasellar tumour was done which was extending to floor and behind the chiasma. Histopathology revealed it to be esthesioneuroblastoma. Postoperatively he received radiotherapy 50 grays / 5 weeks / 25 fractions. He was given Lomustine ( Cap, CCNU) $160 \mathrm{mg}$ twice at 6 weeks interval,

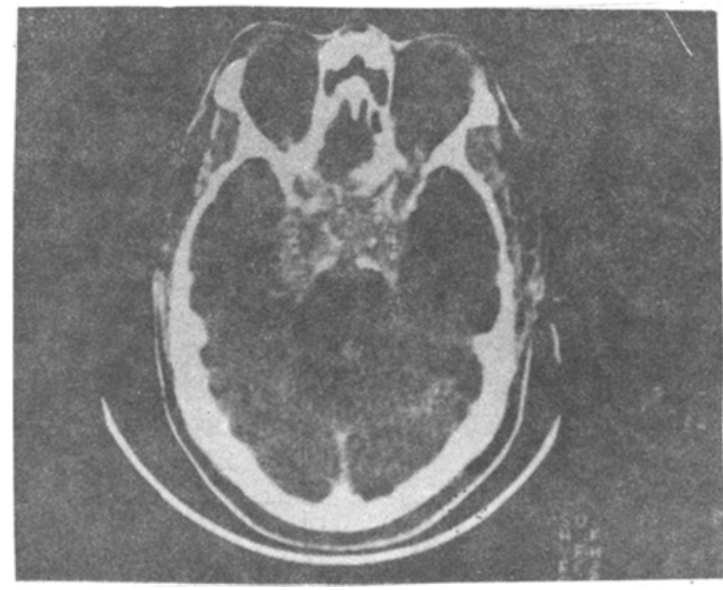

Fig. I. Axial and Coronal section at level of sella showing its destruction with parasellar extension.

Patient is doing well after 1 year and 9 months of follow up. His field of vision and ENT examination is normal and there is no evidence of metastatic disease.

\section{Review of Literature and Discussion}

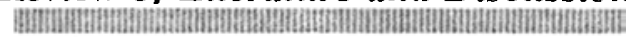

Esthesioneuroblastoma (ENB) is a rare neoplasm (till 1990, 250 cases were reported) of neuroectodermal origin, arising from olfactory epithelium of superior nasal cavity in close proximity to cribriform plate. Peak incidence is in third or fourth decade, with 


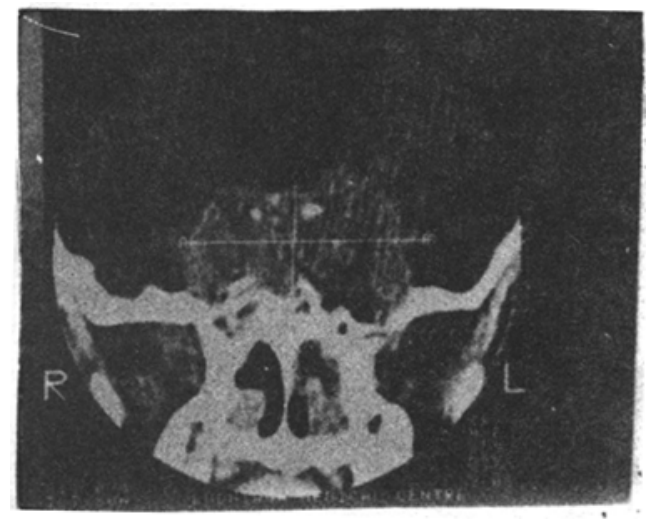

Fig. 2. Axial and Coronal section at level of sella showing its destruction with parasellar extension.

range from 3,to 79 years. Common presenting symptoms are nasal obstruction $63 \%$, Epistaxis $57 \%$, Orbital symptoms $53 \%$ Headache $27 \%$ and Anosmia $13 \%$. Generally symptoms antedate diagnosis on average by 12 months (Spalding et al 1988). Lymphnode metastais is variably reported as 10 to $50 \%$. Distant metastases occur in $17 \%$ of patients, commonly to bones (D. Angio and Evans 1989.

The sine qua non for light Microscopic diagnosis of esthesioneuroblastoma is the presence of fibrillary intercellular background which has been found on electron microscopic to represent neuronal cell processes. Homer-Wright rostters, an annulus of cells surrounding a core of eosinophilic fibrils are diagnostic of esthesioneuroblastoma (Spalding et al 1988). It has been often difficult to differentiate it from malignant melanoma, rhabdomyosarcoma, undifferentiated carcinoma and extramedullary plasmocytoma ( Abrams et al 1987).

Kadish et al (1976) have proposed the following staging system for esthesioneuroblastoma :-

Stage A-Disease confined to the nasal cavity.

Stage B - Disease ex tending beyond nasal cavity to one or more paranasal sinuses.

Stage C - Disease extending beyond to orbit, base of skull intracranial cavity, lymphnodes or distant metastases.

Overall local recurrance rate is 26 to $57 \%$ ( $D^{\prime}$ Angio and Evans, 1989) and $86 \%$ patients who have to relapse presented within 2 years. Overall survival at 2 and 5 years is $80 \%$ and $61 \%$ respectively (Homzie and Elkon 1980 and Elkon D 1983).

The optimal therapy for esthesioneuroblastoma has not yet been determined properly. There are strong proponents of radiotherapy alone, surgery alone and combined modality therapy including chemotherapy (Goldsweig and Sundersan 1990). Wide excision of tumour usually result in better survival. Bone marrew trans plantation have been done with some success in metastatic disease (Steward et al 1989).

\section{References}

1. Abrams RA, Wilson J.F., Komorowski RA, Collins D. Toohil R. S. (1987): Esthesioneuroblastoma masguerading as extra-medullary plasmacytoma. Cancer $60: 88-89$.

2. Dr. Angio G. J. Evans A. E. (1989): Esthesioneuroblastoma, Medical and Paediatric Oncology 17 : 433-438.

3. Elkon D. (1983): Olfactory esthesioneuroblastoma in nasal tumours in animals and man, Vol II, Boca Raton, CRC Press Inc. 129-147.

4. Goldsweig H. G. Sunderesan N (1990): Chemotherapy of recurrent Esthesioneunoblastoma American Journal of Clinical Oncology 13 (2) : $139-143-1990$.

5. Homzie M. J. Elkon D. (1980): Olfactory eshesioneuroblastoma-variable predictive of tumour control and recurrance. Cancer $46: 2509-2513$.

6. Kadish S., Goodman. M, Wang CC : (1976) : Olfactory neuroblastoma. A clinical analysis of 17 cases : Cancer 37 : 1571-1576.

7. Spaulding CA, Kranyak M. S., Constable W.C., Steward F.M. (1988): Esthesioneuroblastoma : A comparision of two treatment eras, International Journal of Radiation Biology and Physics $15: 581-590$.

8 Steward, F.M. Lazarus, H. M., Leveine, P.A., Stewart, K.K. Tabbere IA, Spaulding CA (1989): High dose chemotherapy and autologous marrow transplantation for esthesionèuroblastoma and sinonasal undifferentiated carcinoma; American Journal of Clinical Oncology 12 (3) : 217-221. 